\title{
Once-Daily Triple Therapy in Patients with COPD: Patient-Reported Symptoms and Quality of Life
}

\author{
Maggie Tabberer - David A. Lomas · Ruby Birk · Noushin Brealey \\ Chang-Qing Zhu $\cdot$ Steve Pascoe $\cdot$ Nicholas Locantore $\cdot$ David A. Lipson
}

Received: October 16, 2017 / Published online: January 8, 2018

(C) The Author(s) 2018. This article is an open access publication

\section{ABSTRACT}

Introduction: Directly recorded patient experience of symptoms and health-related quality of life (HRQoL) can complement lung function and exacerbation rate data in chronic obstructive pulmonary disease (COPD) clinical studies.

Enhanced content To view enhanced content for this article go to http://www.medengine.com/Redeem/ 2CFCF060057EC87C.

Electronic supplementary material The online version of this article (https://doi.org/10.1007/s12325017-0650-4) contains supplementary material, which is available to authorized users.

M. Tabberer $(\bowtie)$

Value Evidence and Outcomes, GSK, Stockley Park, UK

e-mail: margaret.x.tabberer@gsk.com

D. A. Lomas

UCL Respiratory, University College London,

London, UK

R. Birk · N. Brealey

Respiratory Clinical Development, GSK, Stockley

Park, UK

C.-Q. Zhu

Clinical Statistics, GSK, Stockley Park, UK

S. Pascoe $\cdot$ N. Locantore $\cdot$ D. A. Lipson Respiratory Research and Development, GSK, King of Prussia, PA, USA

D. A. Lipson

Perelman School of Medicine, University of

Pennsylvania, Philadelphia, PA, USA
The FULFIL study recorded daily symptoms and activity limitation together with additional patient-reported outcomes of dyspnea and HRQoL, as part of the prespecified analyses. FULFIL co-primary endpoint data have been previously reported.

Methods: FULFIL was a phase III, 24-week, randomized, double-blind, double-dummy, multicenter study comparing once-daily single inhaler triple therapy [fluticasone furoate/umeclidinium/vilanterol (FF/UMEC/VI)] $100 \mu \mathrm{g} /$ $62.5 \mu \mathrm{g} / 25 \mu \mathrm{g}$ with twice-daily inhaled corticosteroid/long-acting $\quad \beta_{2}$-agonist therapy [budesonide/formoterol (BUD/FOR)] $400 \mu \mathrm{g} /$ $12 \mu \mathrm{g}$ in patients with symptomatic COPD at risk of exacerbations. A subset participated for 52 weeks. Patient-reported assessments were: Evaluating Respiratory Symptoms in $\mathrm{COPD}^{\mathrm{TM}}$ (E-RS: COPD), St George's Respiratory Questionnaire (SGRQ) for COPD, COPD Assessment Test (CAT), baseline and transitional dyspnea indices (TDI) and daily and global anchor questions for activity limitation.

Results: FF/UMEC/VI showed greater reductions from baseline in 4-weekly mean E-RS: COPD total and all subscale scores compared with BUD/FOR; differences were statistically significant $(P<0.05)$ at each time period. $\mathrm{FF} /$ UMEC/VI also demonstrated greater improvements from baseline at weeks 4 and 24 in SGRQ domain scores and TDI focal score compared with BUD/FOR. At weeks 4 and 24, improvements greater than the minimal clinically 
important difference from baseline were observed in CAT score with FF/UMEC/VI, but not BUD/FOR; differences were statistically significant $(P \leq 0.003)$.

Conclusion: These findings demonstrate sustained daily symptom and HRQoL benefits of FF/UMEC/VI versus BUD/FOR. The inclusion of the CAT may provide data that are readily generalizable to everyday clinical practice.

Trial registration: ClinicalTrials.gov number: NCT02345161.

Funding: GSK.

Keywords: Budesonide/formoterol; COPD burden; Fluticasone furoate/umeclidinium/ vilanterol; Patient-reported outcomes; Respiratory; Symptom burden

\section{INTRODUCTION}

Incorporating the patient perspective into clinical studies is an important aspect of drug development [1, 2]. Poor health-related quality of life (HRQoL) in chronic obstructive pulmonary disease (COPD) has been linked to the impact of symptoms such as dyspnea, as well as to physical impairment, decreased mental health, and increased hospital readmission [3-6]. Furthermore, some reports suggest that improving HRQoL reduces economic and social burdens on both individuals and society $[7,8]$. Patient-reported outcome (PRO) measures are therefore important when assessing the overall impact of COPD. The inclusion in clinical development of reliable tools to assess symptoms and HRQoL can, therefore, provide information that complements other efficacy measures, giving a more comprehensive view of the response to treatment and guiding clinical practice [9].

Comparative patient-reported data for COPD therapies are limited, $[10,12]$ with some initial reports suggesting an improvement in HRQoL with open triple therapy compared with dual therapy in patients with symptomatic COPD [10-12]. FULFIL (NCT02345161; GSK study CTT116853) is the first study to compare oncedaily single inhaler triple therapy with fluticasone furoate/umeclidinium/vilanterol (FF/UMEC/VI)
$100 \mu \mathrm{g} / 62.5 \mu \mathrm{g} / 25 \mu \mathrm{g}$ using the ELLIPTA ${ }^{\circledR}$ inhaler with twice-daily dual therapy with budesonide/formoterol (BUD/FOR) $400 \mu \mathrm{g} / 12 \mu \mathrm{g}$ using the Turbuhaler ${ }^{\circledR}$ in patients with symptomatic COPD at risk of exacerbations [13]. Previously published findings showed significant improvements in the co-primary endpoints of lung function and HRQoL as measured by the COPD-specific St George's Respiratory Questionnaire (SGRQ), and in exacerbation rates at week 24 with FF/UMEC/VI compared with BUD/FOR [13]. The safety profile of FF/ UMEC/VI was consistent with the known safety profiles of the individual dual- and monotherapy components [13]. In addition, FULFIL was also designed to prospectively assess symptoms and physical activity, using daily and periodic PRO assessment in patients receiving FF/UMEC/ VI or BUD/FOR. The COPD Assessment Test (CAT) was also included as an additional measure of health status directly relevant to clinical practice [13].

\section{METHODS}

FULFIL was a phase III, randomized, doubleblind, double-dummy, parallel-group, multicenter study (Fig. S1 in the online data supplement) [13]. Co-primary outcomes evaluated the effects of fluticasone furoate/umeclidinium/vilanterol (FF/UMEC/VI) on trough forced expiratory volume in $1 \mathrm{~s}\left(\mathrm{FEV}_{1}\right)$ and St George's Respiratory Questionnaire (SGRQ) [14] total score compared with budesonide/formoterol (BUD/FOR) after 24 weeks of treatment. Secondary and other endpoints that were part of the primary reporting from FULFIL included respiratory symptoms severity (Evaluating Respiratory Symptoms in COPD $^{\mathrm{TM}}$ [E-RS: COPD] and subscales $[15,16]$, Transition Dyspnea Index [TDI] focal score [17-19], and Global Rating of Change in COPD Severity), rescue medication use, and inhaler preference [13]. The CAT was included as an additional HRQoL endpoint so as to provide information on health status using data that can be incorporated easily into clinical practice, provide additional data on the relationship to SGRQ total score, and relate to the Global Initiative for 
Chronic Obstructive Lung Disease assessment of COPD severity [20-22].

\section{Patients}

FULFIL enrolled male and female patients with COPD aged $\geq 40$ years with symptomatic COPD at risk of exacerbation:

- CAT score $\geq 10$,

- And either

- forced expiratory volume in $1 \mathrm{~s}<50 \%$ (no exacerbation history requirement)

- or forced expiratory volume in $1 \mathrm{~s}$ $50-80 \%$ with a history of exacerbations in the previous year ( $\geq 2$ moderate or $\geq 1$ exacerbation requiring hospitalization).

Patients were randomized to receive 24 weeks of once-daily FF/UMEC/VI $(100 \mu \mathrm{g} /$ $62.5 \mu \mathrm{g} / 25 \mu \mathrm{g})$ using a single ELLIPTA ${ }^{\circledR}$ inhaler or twice-daily BUD/FOR $(400 \mu \mathrm{g} / 12 \mu \mathrm{g})$ using the Turbuhaler ${ }^{\circledR}$ (intent-to-treat [ITT] population) [13]. A subset of patients remained on blinded study treatment for up to 52 weeks [extension (EXT) population].

Patients were required to be receiving daily maintenance therapy for chronic obstructive pulmonary disease (COPD) for $\geq 3$ months, with medications at screening that continued unchanged during the 2-week run-in period. Patients were excluded if they had a current diagnosis of asthma, COPD caused by $\alpha 1$-antitrypsin deficiency, other respiratory disorders, lung resection within 12 months of screening, or any other clinically significant diseases. Patients who had pneumonia or a severe COPD exacerbation that had not resolved within 14 days of screening, a respiratory tract infection that had not resolved within 7 days of screening, or an abnormal chest X-ray were also excluded.

The study protocol was reviewed and approved by the relevant investigational center ethics committee or institutional review board, in accordance with the International Council on Harmonisation. The study was conducted in accordance with the Declaration of Helsinki and all participants provided written informed consent.

\section{Patient-Reported Outcome Tools}

Patients used an electronic diary each evening to complete the E-RS: COPD [derived from EXAcerbations of Chronic pulmonary disease Tool (EXACT)], record rescue medication use, and limitation in daily activities questions. The COPD-specific SGRQ and CAT were used to assess HRQoL at study visits; this article reports SGRQ domain scores of symptoms, activity, and impacts (total score results have been previously reported elsewhere) [13]. The TDI focal score (self-administered computerized version) was used to assess dyspnea. Global Ratings of COPD Severity and activity limitation were assessed at randomization, and Global Rating of Change from Baseline in Severity and activity limitation at all visits post-randomization. The doubledummy study design enabled patients to express preference between the inhalers; responses were obtained using the COPD Inhaler Preference Questionnaire at week 24 (or at treatment discontinuation, if applicable) [23]. Patients were asked which inhaler they preferred, based on number of steps, time taken, and ease of use: the response options were ELLIPTA, Turbuhaler or no preference. The form and timing of these assessments are summarized in Table 1.

\section{Statistical Analyses}

Prespecified analyses were performed in the ITT population for data up to week 24 , and in the EXT population for data up to week 52. Mean scores for the E-RS: COPD and the three subscales over 4-week intervals, change from baseline in CAT scores, TDI focal scores, and mean number of occasions of rescue medication use per day over the 4-week intervals were all analyzed using a mixed model repeat measures analysis including treatment group, smoking status at screening, geographical region, visit, baseline value, and baseline-by-visit and treatment group-by-visit interactions. The proportions of responders on SGRQ, CAT, E-RS: COPD and TDI (response defined as a change from baseline equal to or greater than MCID [Table 1]) and non-responders were analyzed 
Table 1 Assessment tools used in patient-reported data collection

\begin{tabular}{|c|c|c|}
\hline Assessment tools & Time points completed ${ }^{a}$ & Summary \\
\hline E-RS: COPD $[15,16]$ & Daily & $\begin{array}{l}11 \text { respiratory symptom items contained in } \\
\text { the 14-item EXACT } \\
\text { Total score represents overall respiratory } \\
\text { symptom severity and the three subscales } \\
\text { assess breathlessness, cough and sputum, } \\
\text { and chest-related symptoms } \\
\text { MCID: } \geq 2 \text {-unit improvement (decrease) } \\
\text { from baseline for total score }\end{array}$ \\
\hline CAT $[20,21]$ & $\begin{array}{l}\text { Baseline, day 1, weeks } 4 \text { and } 24 \text {, } \\
\text { week } 52 \text { (EXT) }\end{array}$ & $\begin{array}{l}\text { Eight items, each with a 6-point response } \\
\text { scale, ranging from } 0 \text { (no impact) to } 5 \\
\text { (high impact) with a scoring range of } \\
0-40 \\
\text { MCID } \geq 2 \text {-unit improvement (decrease in } \\
\text { score) from baseline }\end{array}$ \\
\hline Rescue medication use & Daily & $\begin{array}{l}\text { Number of occasions of rescue medication } \\
\text { use per day }\end{array}$ \\
\hline TDI focal score $[17-19]$ & $\begin{array}{l}\text { Weeks } 4 \text { and 24, week } 52 \\
(\text { EXT) }\end{array}$ & $\begin{array}{l}\text { Change in dyspnea severity on a } 7 \text {-point } \\
\text { scale ranging from major deterioration to } \\
\text { major improvement } \\
\text { MCID: } \geq 1 \text {-unit improvement (increase) }\end{array}$ \\
\hline SGRQ-C [14] & $\begin{array}{l}\text { Day } 1 \text {, week } 4 \text { and } 24 \text {, week } 52 \\
\text { (EXT) }\end{array}$ & $\begin{array}{l}40 \text { items weighted by symptoms, activity, } \\
\text { and impacts with a scoring range of } \\
0-100 \\
\text { Domain scores are calculable for symptoms, } \\
\text { activity, and impact } \\
\text { MCID } \geq 4 \text {-unit improvement (decrease in } \\
\text { score) from baseline }\end{array}$ \\
\hline Global rating of COPD severity & $\begin{array}{l}\text { Baseline, week 24, and } 52 \\
\quad(\mathrm{EXT})\end{array}$ & $\begin{array}{l}\text { 4-point scale (mild, moderate, severe, very } \\
\text { severe) }\end{array}$ \\
\hline Rating of change in COPD severity & $\begin{array}{l}\text { All study visits following } \\
\text { baseline }\end{array}$ & $\begin{array}{l}\text { Change rated on a 7-point Likert scale } \\
\text { (much better, better, slightly better, no } \\
\text { change, slightly worse, worse, much worse) }\end{array}$ \\
\hline Daily activity question & $\begin{array}{l}\text { Baseline, week 24, and } 52 \\
(\text { EXT) }\end{array}$ & $\begin{array}{l}\text { 3-point scale: } 0=\mathrm{I} \text { did fewer activities than } \\
\text { usual; } 1=\text { There was no effect on my } \\
\text { activities; } 2=\mathrm{I} \text { did more activities than } \\
\text { usual }\end{array}$ \\
\hline
\end{tabular}


Table 1 continued

\begin{tabular}{lll}
\hline Assessment tools & Time points completed $^{\mathbf{a}}$ & Summary \\
\hline Global rating of activity limitation & Baseline, week 24, and 52 & $\begin{array}{c}\text { Activity limitation rated on a 4-point scale } \\
\text { (not limited, slightly limited, limited, very }\end{array}$ \\
Rating of change in activity limitation & All study visits following & limited) \\
& baseline & Change rated on a 7-point Likert scale \\
& & (much better, better, slightly better, no \\
& & change, slightly worse, worse, much worse) \\
CIPQ & Week 24 (or study treatment & $\begin{array}{c}\text { Three questions regarding number of steps, } \\
\text { time taken, and ease of use }\end{array}$ \\
\hline
\end{tabular}

CAT COPD Assessment Test, CIPQ COPD Inhaler Preference Questionnaire, COPD chronic obstructive pulmonary disease, E-RS: COPD Evaluating Respiratory Symptoms in COPD, EXACT EXAcerbations of Chronic pulmonary disease Tool, EXT extension, $M C I D$ minimal clinically important difference, SGRQ-C St George's Respiratory Questionnaire for COPD, TDI Transition Dyspnea Index

${ }^{a}$ All time points specified are for the ITT population, unless otherwise specified

using a generalized linear mixed model with a logit link function. Number need to treat to benefit was calculated (post hoc) for E-RS: COPD, TDI, CAT and SGRQ total scores.

The proportion of days that a patient reported a score of 0 (less activity than usual), 1 (the same activity as usual), or 2 (more activity than usual) on the daily activity question was determined for the weeks 1-24 period for the ITT population and weeks $1-52$ for the EXT population. The proportion of days with a score of 2 (able to perform more activities than usual) on the daily activity question was analyzed using an analysis of covariance model and included the following covariates: treatment group, screening smoking status, geographical region, and baseline value. Patient Global Ratings of Change in Activity Limitation and Change in COPD Severity were analyzed separately at each visit, using logistic regression including treatment, screening smoking status, and geographical region as covariates. The proportion of patients who reported a preference for either inhaler or no preference was presented. For patients who expressed a preference for either ELLIPTA $^{\circledR}$ or Turbuhaler ${ }^{\circledR}, P$ values were calculated (post hoc) to test whether the proportion of patients who preferred ELLIPTA ${ }^{\circledR}$ differed significantly from $50 \%$.

\section{RESULTS}

The ITT population comprised 1810 patients (FF/UMEC/VI, $n=911$; BUD/FOR, $n=899$ ). The EXT population included the first 430 of these patients who consented to receive treatment for 52 weeks (FF/UMEC/VI, $n=210 ; \mathrm{BUD} / \mathrm{FOR}$, $n=220$ ) (Fig. 1). The full population characteristics are shown in Table S1 in the online data supplement, as reported in the primary publication [13]. Baseline demographics and PRO scores were similar between treatment arms in both the ITT and EXT populations, and between the ITT and EXT populations (Table 2) [13]. COPD maintenance medication taken at screening was comparable between treatment arms and the ITT and EXT populations (Table S2).

\section{Symptom Assessments}

Over 24 weeks (ITT), FF/UMEC/VI produced greater reductions from baseline in mean E-RS: COPD total score and all subscale scores compared with BUD/FOR; treatment differences were statistically significant for each 4 -week interval and in the FF/UMEC/VI group exceeded the total score response threshold by week 8 . Breathlessness and cough and sputum subscales 


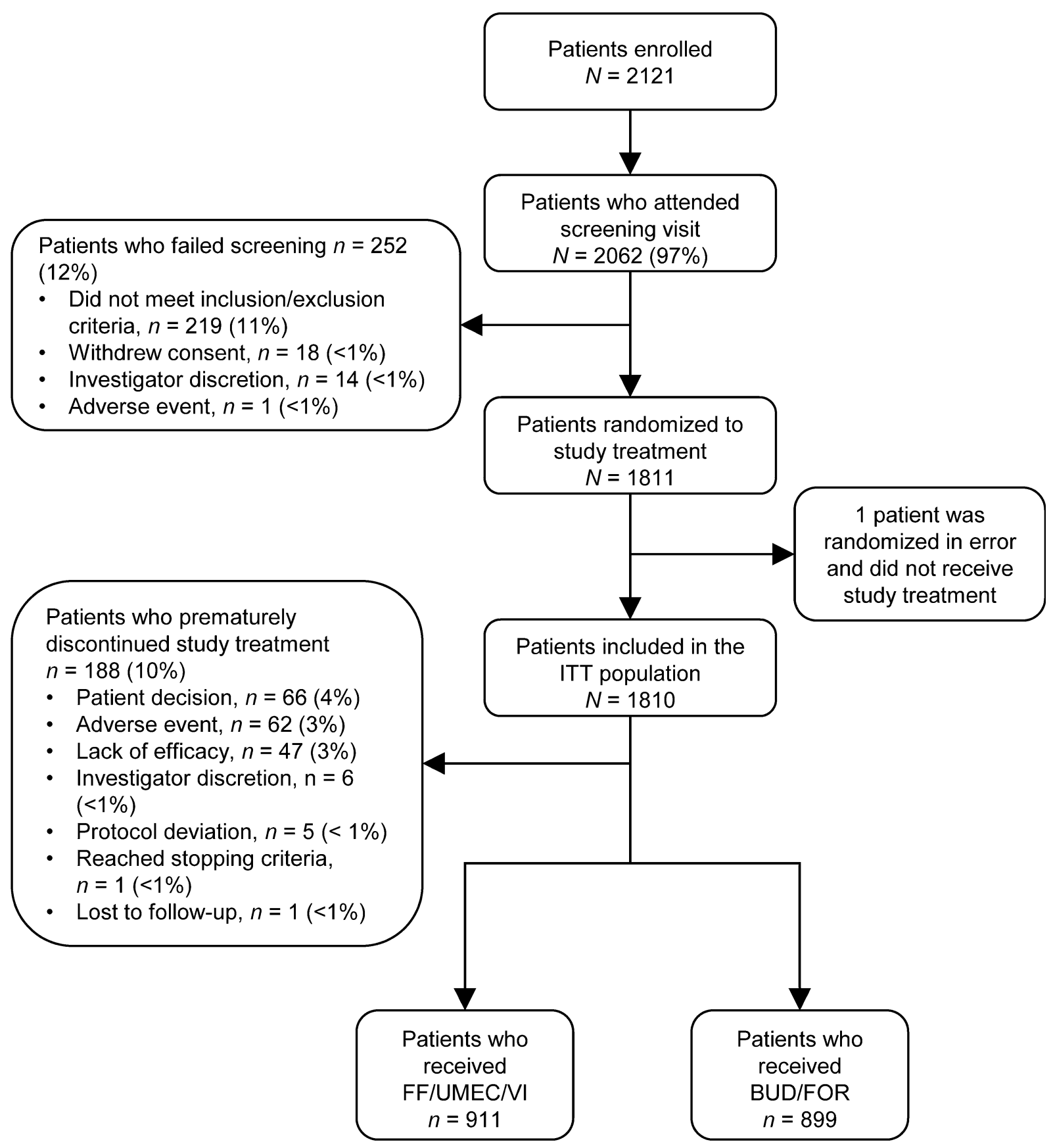

Fig. 1 CONSORT flow chart for the FULFIL study. BUD/FOR budesonide/formoterol, FF/UMEC/VI fluticasone furoate/umeclidinium/vilanterol, ITT intent-to-treat

in this group exceeded the threshold by week 12 (Fig. 2). The between-treatment odds ratios (ORs) of response versus non-response over 24 weeks (ITT) were statistically significant in favor of FF/UMEC/VI (OR range over 24 weeks, 1.59-1.76; all $P<0.001$ ). At weeks $21-24$ (ITT) for FF/UMEC/VI versus BUD/FOR, 53 and $42 \%$ of patients responded, respectively, and the number needed to treat to benefit (NNTB) was 9 (95\% CI 7-17). Similar findings were observed for OR response versus not response at each 4 -week interval over 52 weeks in the EXT 
Table 2 Patient characteristics at baseline (ITT and EXT populations)

\begin{tabular}{|c|c|c|c|c|}
\hline \multirow[t]{2}{*}{ Baseline characteristic } & \multicolumn{2}{|c|}{ ITT population ( 24 weeks) } & \multicolumn{2}{|c|}{ EXT population ( 52 weeks) } \\
\hline & $\begin{array}{l}\text { FF/UMEC/VI } \\
100 / 62.5 / 25 \mu \mathrm{g} \\
(n=911)\end{array}$ & $\begin{array}{l}\text { BUD/FOR } \\
400 / 12 \mu \mathrm{g} \\
(n=899)\end{array}$ & $\begin{array}{l}\text { FF/UMEC/VI } \\
100 / 62.5 / 25 \mu \mathrm{g} \\
(n=210)\end{array}$ & $\begin{array}{l}\text { BUD/FOR } \\
400 / 12 \mu \mathrm{g} \\
(n=220)\end{array}$ \\
\hline Mean age, years (SD) & $64.2(8.56)$ & $63.7(8.71)$ & $63.7(7.76)$ & $63.3(8.43)$ \\
\hline Female, $n(\%)$ & $233(26)$ & $236(26)$ & $53(25)$ & $58(26)$ \\
\hline $\mathrm{FEV}_{1}$, mean $(\mathrm{SD})$ & $1.28(0.46)$ & $1.27(0.47)$ & $1.33(0.50)$ & $1.28(0.48)$ \\
\hline$\%$ Predicted $\mathrm{FEV}_{1}$, mean $(\mathrm{SD})$ & $42.5(13.01)$ & $41.8(13.48)$ & $44.1(13.36)$ & $41.7(14.07)$ \\
\hline E-RS: COPD total score, mean (SD) & $13.20(5.83)$ & $12.97(5.93)$ & $13.54(5.44)$ & $13.00(5.58)$ \\
\hline \multicolumn{5}{|l|}{ SGRQ domain scores, mean (SD) } \\
\hline Symptoms & $67.4(18.35)$ & $67.2(18.71)$ & $70.0(18.65)$ & $68.7(18.79)$ \\
\hline Activity & $64.2(17.64)$ & $63.1(18.28)$ & $65.1(17.73)$ & $62.6(16.57)$ \\
\hline Impacts & $39.9(19.48)$ & $38.6(19.98)$ & $40.8(19.32)$ & $38.4(18.36)$ \\
\hline CAT score, mean (SD) & $17.6(6.43)$ & $17.8(6.24)$ & $18.1(6.29)$ & $17.7(5.93)$ \\
\hline \multicolumn{5}{|l|}{ Global rating of COPD severity, $n(\%)$} \\
\hline Mild & $89(10)$ & $92(10)$ & $12(6)$ & $21(10)$ \\
\hline Moderate & $594(66)$ & $604(68)$ & $143(68)$ & $152(70)$ \\
\hline Severe & $207(23)$ & $181(20)$ & $51(24)$ & $42(19)$ \\
\hline Very severe & $12(1)$ & $7(<1)$ & $3(1)$ & $2(<1)$ \\
\hline \multicolumn{5}{|l|}{ Global rating of activity limitation, $n$ (\%) } \\
\hline Not limited & $47(5)$ & $43(5)$ & $7(3)$ & $5(2)$ \\
\hline Slightly limited & $366(41)$ & $382(43)$ & $77(37)$ & $94(43)$ \\
\hline Limited & $424(47)$ & $404(46)$ & $107(51)$ & $102(47)$ \\
\hline Very limited & $63(7)$ & $55(6)$ & $18(9)$ & $16(7)$ \\
\hline $\begin{array}{l}\text { Number of occasions of rescue medication } \\
\text { use per day, mean (SD) }\end{array}$ & $1.8(2.07)$ & $1.8(2.04)$ & $1.6(1.95)$ & $1.5(1.87)$ \\
\hline
\end{tabular}

BUD/FOR budesonide/formoterol, CAT COPD Assessment Test, COPD chronic obstructive pulmonary disease, E-RS: $C O P D$ Evaluating Respiratory Symptoms in COPD, EXT extension, FEV forced expiratory volume in $1 \mathrm{~s}, F F / U M E C / V I$ fluticasone furoate/umeclidinium/vilanterol, ITT intent-to-treat, $S D$ standard deviation, SGRQ St George's Respiratory Questionnaire

population [Table S23 in the online data supplement; proportion of responders: 42 and 32\% for $\mathrm{FF} / \mathrm{UMEC} / \mathrm{VI}$ and $\mathrm{BUD} / \mathrm{FOR}$, respectively; NNTB of 10 (95\% CI 5-77)].

FF/UMEC/VI also demonstrated statistically significant improvements in dyspnea, measured by mean TDI focal score, compared with BUD/ FOR at weeks 4 and 24 in the ITT population (Table 3). Between-treatment ORs of response versus non-response at weeks 4 and 24 (ITT) were statistically significant in favor of $\mathrm{FF} /$ UMEC/VI [week 4 OR $(95 \%$ CI $): 1.52$ 

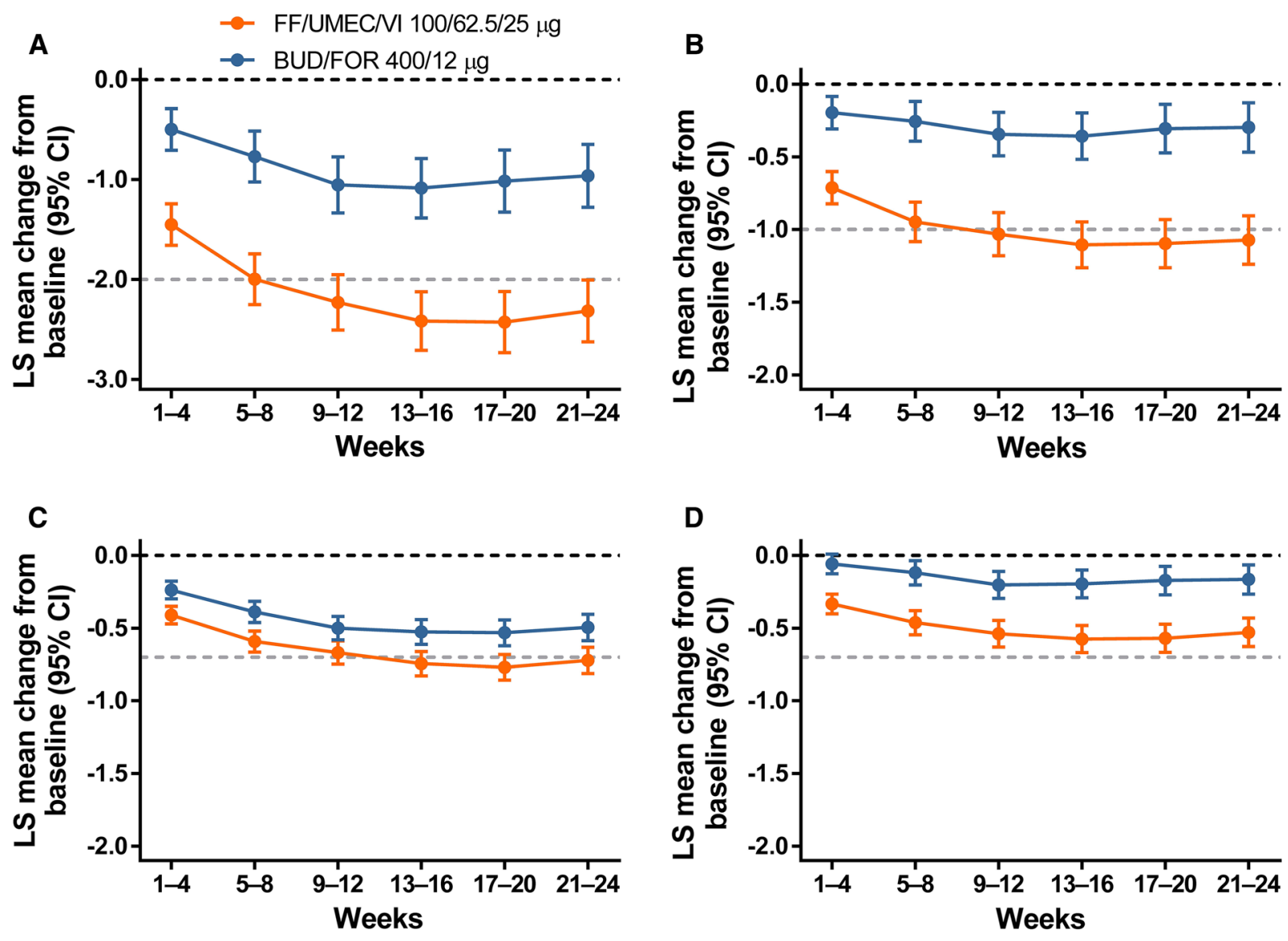

Fig. 2 Mean change from baseline in 4-weekly E-RS: COPD scores (ITT): total score (a); breathlessness (b); cough and sputum (c); chest symptoms (d). Dark dotted lines represent baseline and light dotted lines represent response threshold. BUD/FOR budesonide/formoterol, $C I$

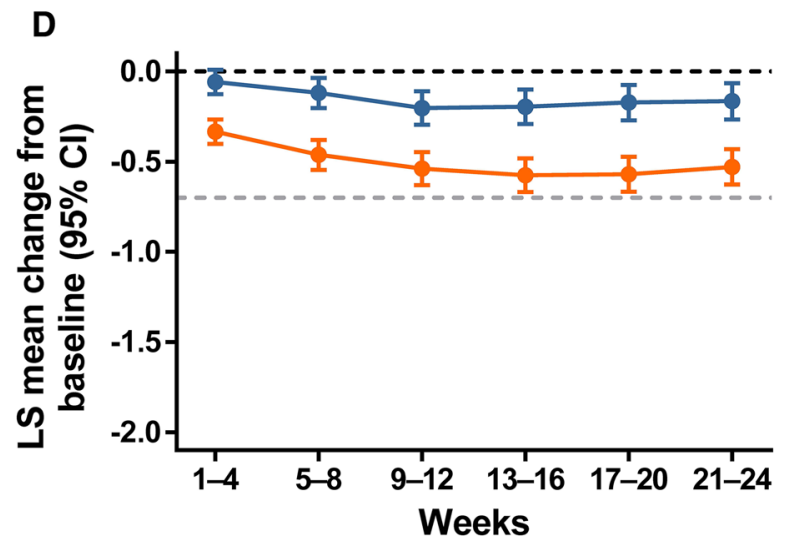

confidence interval, E-RS: COPD Evaluating Respiratory Symptoms in COPD, FF/UMEC/VI fluticasone furoate/ umeclidinium/vilanterol, ITT intent-to-treat, $L S$ least squares

(1.25-1.86), $P>0.001$; week 24 OR $(95 \% \mathrm{CI})$ : 1.61 (1.33-1.95), $P<0.001]$. At week 24 (ITT), 61 and $51 \%$ of patients responded on FF/UMEC/ VI and BUD/FOR, respectively, and the NNTB was 10 (95\% CI 7-18). In the EXT population at week 52, there was no evidence of benefit, the OR was $1.35(P=0.1 .32)$ and 53 and $46 \%$ responded, respectively. The mean TDI focal score showed numeric improvement with FF/ UMEC/VI compared with BUD/FOR at weeks 4, 24 , and 52 (EXT) but only achieved statistical significance at week $4(P=0.01)$. However, the ratio between treatments of odds of response versus non-response for the E-RS: COPD Breathlessness Score for each 4-weekly period in the EXT population ranged from 1.60 to 2.32

(all $P<0.05$ ). The observed improvements in symptom scores were independent of baseline COPD medication.

A statistically significant reduction in mean number of occasions of rescue medication use per day was demonstrated with FF/UMEC/VI versus BUD/FOR over weeks 1-24 (ITT) and weeks 1-52 (EXT) (Table 4). Similar findings were observed at each 4-week time period (Table 4).

\section{HRQoL Assessments}

In the ITT population at weeks 4 and 24, clinically meaningful improvements from baseline in CAT score (reduction $\geq 2$ ) were observed with 
Table 3 Analysis of TDI focal scores and proportion of TDI responders in the ITT and EXT populations

\begin{tabular}{|c|c|c|c|c|}
\hline \multirow[t]{2}{*}{ TDI focal score } & \multicolumn{2}{|c|}{ ITT population (24 weeks) } & \multicolumn{2}{|c|}{ EXT population ( 52 weeks) } \\
\hline & $\begin{array}{l}\text { FF/UMEC/VI } \\
100 / 62.5 / 25 \mu \mathrm{g} \\
(n=911)\end{array}$ & $\begin{array}{l}\text { BUD/FOR } \\
400 / 12 \mu \mathrm{g} \\
(n=899)\end{array}$ & $\begin{array}{l}\text { FF/UMEC/VI } \\
100 / 62.5 / 25 \mu \mathrm{g} \\
(n=210)\end{array}$ & $\begin{array}{l}\text { BUD/FOR } \\
400 / 12 \mu \mathrm{g} \\
(n=220)\end{array}$ \\
\hline Baseline dyspnea index, mean (SD) & $5.7(1.77)$ & $5.5(1.83)$ & $5.9(1.58)$ & $5.5(1.70)$ \\
\hline \multicolumn{5}{|l|}{ Week 4} \\
\hline LS mean $(95 \% \mathrm{CI})$ & $1.78(1.61-1.96)$ & $1.29(1.11-1.47)$ & $1.66(1.28-2.04)$ & $0.96(0.58-1.33)$ \\
\hline Difference $(95 \% \mathrm{CI})$ & $0.49(0.24-0.75)$ & & $0.71(0.17-1.24)$ & \\
\hline$P$ value & $<0.001$ & & 0.010 & \\
\hline \% Responders & 58 & 49 & 55 & 46 \\
\hline OR (95\% CI) & $1.52(1.25-1.86)$ & & $1.51(1.01-2.26)$ & \\
\hline$P$ value & $<0.001$ & & 0.047 & \\
\hline \multicolumn{5}{|l|}{ Week 24} \\
\hline LS mean $(95 \% \mathrm{CI})$ & $2.29(2.10-2.48)$ & $1.72(1.52-1.91)$ & $1.97(1.56-2.37)$ & $1.70(1.29-2.11)$ \\
\hline Difference $(95 \% \mathrm{CI})$ & $0.57(0.30-0.84)$ & & $0.26(-0.32$ to 0 & \\
\hline$P$ value & $<0.001$ & & 0.373 & \\
\hline$\%$ Responders & 61 & 51 & 60 & 52 \\
\hline OR $(95 \% \mathrm{CI})$ & $1.61(1.33-1.95)$ & & $1.41(0.95-2.09)$ & \\
\hline$P$ value & $<0.001$ & & 0.089 & \\
\hline \multicolumn{5}{|l|}{ Week 52} \\
\hline LS mean $(95 \% \mathrm{CI})$ & & & $1.74(1.30-2.17)$ & $1.39(0.95-1.84)$ \\
\hline Difference $(95 \% \mathrm{CI})$ & & & $0.34(-0.28$ to 0 & \\
\hline$P$ value & & & 0.279 & \\
\hline \% Responders & & & 53 & 46 \\
\hline OR $(95 \% \mathrm{CI})$ & & & $1.35(0.91-1.99)$ & \\
\hline$P$ value & & & 0.132 & \\
\hline
\end{tabular}

TDI focal score range is -9 to 9 (lower scores indicate more deterioration in severity of dyspnea). Response defined as a score of $\geq 1$

$B U D / F O R$ budesonide/formoterol, $C I$ confidence interval, EXT extension, FF/UMEC/VI fluticasone furoate/umeclidinium/vilanterol, $I T T$ intent-to-treat, $L S$ least squares, $O R$ ratio of odds of response versus non-response, $S D$ standard deviation, TDI Transition Dyspnea Index

FF/UMEC/VI (mean change from baseline: week $4,-1.7$; week $24,-2.7$ ), but not with BUD/FOR (mean change from baseline: week $4,-1.4$; week $24,-1.7)$. The treatment differences of -0.7 and -0.9 units, respectively, were statistically significant (Fig. 3). In the smaller EXT population, improvements from baseline were also observed at weeks 4,24 , and 52 with both treatments, numerically in favor of FF/UMEC/ VI, but the treatment difference was only statistically significant at week $24(P=0.035)$. The OR of response versus non-response at week 24 
Table 4 Treatment difference in rescue medication use for $\mathrm{FF} / \mathrm{UMEC} / \mathrm{VI}$ vs BUD/FOR, in the ITT and EXT populations

\begin{tabular}{llr}
\hline $\begin{array}{l}\text { Time period } \\
\text { (population) }\end{array}$ & $\begin{array}{l}\text { Treatment difference, } \\
\text { occasions/day }\end{array}$ & P value \\
\hline Weeks 1-24 (ITT) & -0.2 & $<0.001$ \\
Weeks 1-52 (EXT) & -0.2 & 0.019 \\
Weeks 21-24 (ITT) & -0.3 & $<0.001$ \\
Weeks 49-52 (EXT) & -0.5 & 0.003 \\
\hline
\end{tabular}

$B U D / F O R$ budesonide/formoterol, EXT extension, $F F /$ $U M E C / V I$ fluticasone furoate/umeclidinium/vilanterol, ITT intent-to-treat

(ITT) was statistically significant in favor of FF/ UMEC/VI versus BUD/FOR (OR 1.44, $P<0.001$ ). At week 24 (ITT), 53 and $45 \%$ of patients receiving $\mathrm{FF} / \mathrm{UMEC} / \mathrm{VI}$ or $\mathrm{BUD} / \mathrm{FOR}$ responded, respectively, and the NNTB was 11 (95\% CI 8-29). At week 52 (EXT), the OR was 1.50 $(P=0.048)$ and the proportions of responders were 44 versus 35\%, respectively, [NNTB, 11 (95\% CI 5-459)]. Similar findings were observed in SGRQ analyses. At week 24 (ITT), the OR of response versus non-response was statistically significant in favor of FF/UMEC/VI versus BUD/ FOR (OR 1.41, $P<0.001$ ). At week 24 (ITT), 50 and $41 \%$ of patients receiving FF/UMEC/VI or
BUD/FOR responded, respectively, and the NNTB was 12 (95\% CI 8-27). At week 52 (EXT), the OR was $1.50(P=0.046)$ and the proportions of responders were 44 versus $33 \%$, respectively (NNTB, 10 [95\% CI 5-97]).

Improvements from baseline in SGRQ domain scores were observed in both treatment groups in the ITT population in line with changes in the total score [13], with significantly greater improvements observed with $\mathrm{FF} /$ UMEC/VI across all domain scores compared with BUD/FOR at weeks 4 and 24 (Fig. 4). Improvements from baseline in SGRQ domain scores were also observed in both treatment groups at weeks 4, 24, and 52 in the EXT population numerically in favor of FF/UMEC/VI at all time points, except for Symptoms and Impacts domains at week 4 (Table S3 in the online data supplement).

The FF/UMEC/VI group had significantly greater odds of being in a better versus a worse response category for patient-rated Global Rating of Change in COPD Severity from baseline at week 24 (ITT) compared with BUD/FOR [ordered OR 1.63; 95\% confidence interval (CI) 1.37-1.95] and at week 52 (EXT) population (ordered OR 2.08; 95\% CI 1.42-3.06). All HRQoL findings were observed independent of baseline COPD medication. The relationship between SGRQ and CAT scores was explored

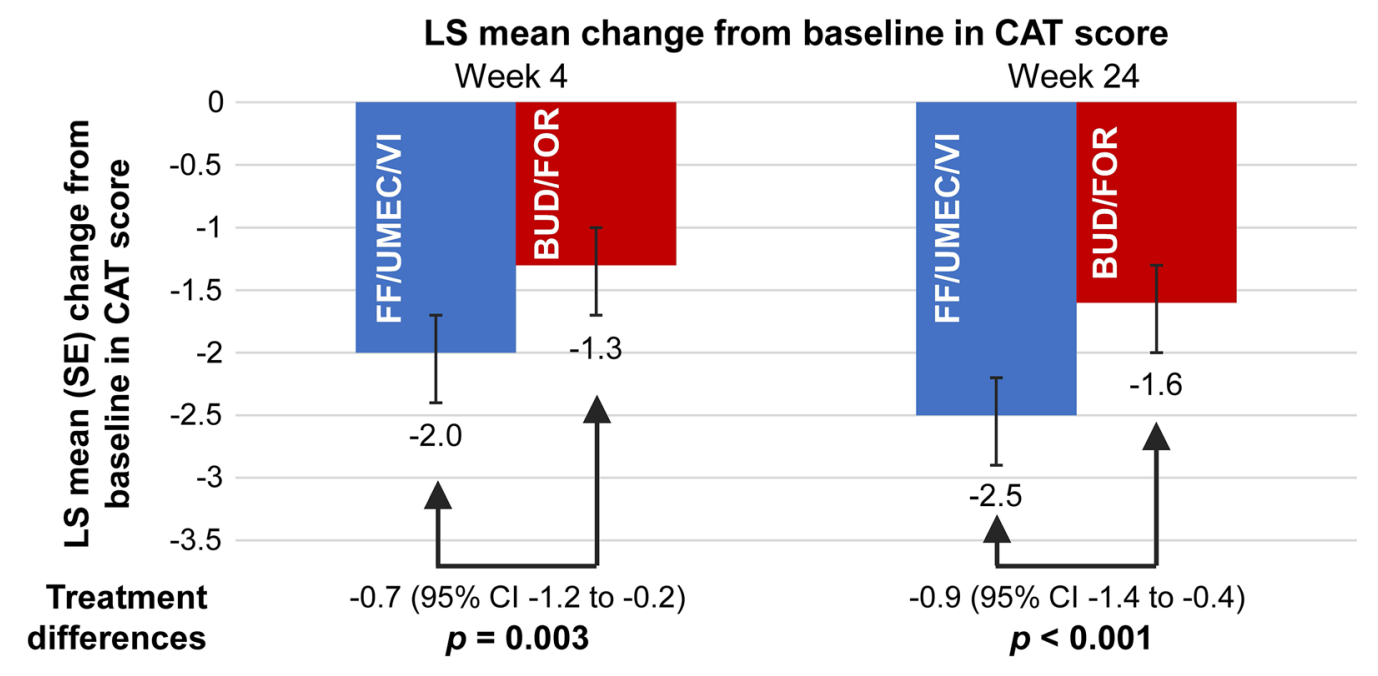

Fig. 3 Mean change in baseline in CAT score in the ITT population. BUD/FOR budesonide/formoterol, $C A T$ COPD Assessment Test, CI confidence interval, FF/

$U M E C / V I$ fluticasone furoate/umeclidinium/vilanterol, $I T T$ intent-to-treat, $L S$ least squares, $S E$ standard error 


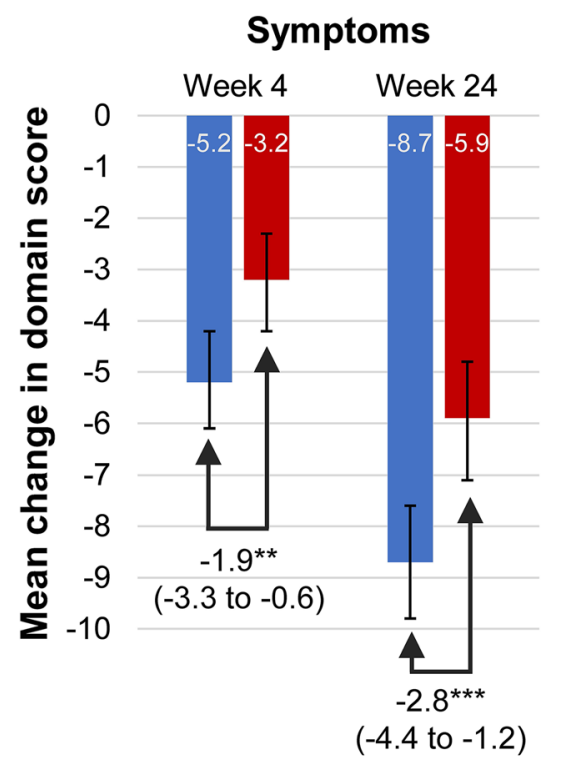

Fig. 4 Mean change from baseline in SGRQ domain scores in the ITT population. Treatment differences (95\% CIs) shown. ${ }^{*} P<0.05$; ${ }^{* *} P<0.01 ;{ }^{* *} P<0.001$. BUD/ FOR budesonide/formoterol, $C I$ confidence interval, $F F /$

post hoc using individual patient data and demonstrated a positive correlation between the changes from baseline in SGRQ total score and in CAT score at week 24 in the ITT population (Fig. 5).

\section{Activity Limitation and Inhaler Preference}

At baseline, most patients reported some level of COPD-related limitation in activity, with similar proportions in each arm reporting slightly limited or limited activity and only a few patients reporting the extremes of no limitation or very limited activity.

At weeks 24 (ITT population) and 52 (EXT population), compared with baseline, more patients treated with FF/UMEC/VI reported improved activity limitation ('not limited' and 'slightly limited' categories) on the Global Rating of Activity Limitation (13 and 15\% increases) compared with BUD/FOR (5\% increases at each week).

Patients receiving FF/UMEC/VI had statistically significantly greater odds of being in a
Activity

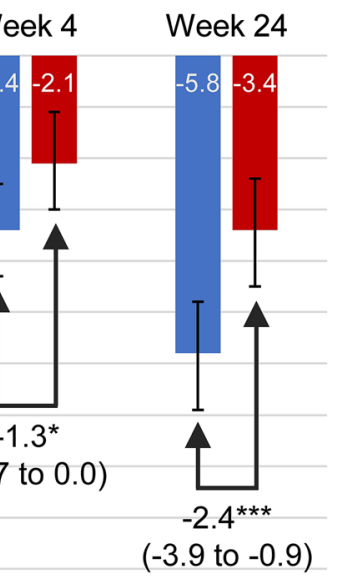

$(-3.9$ to -0.9$)$

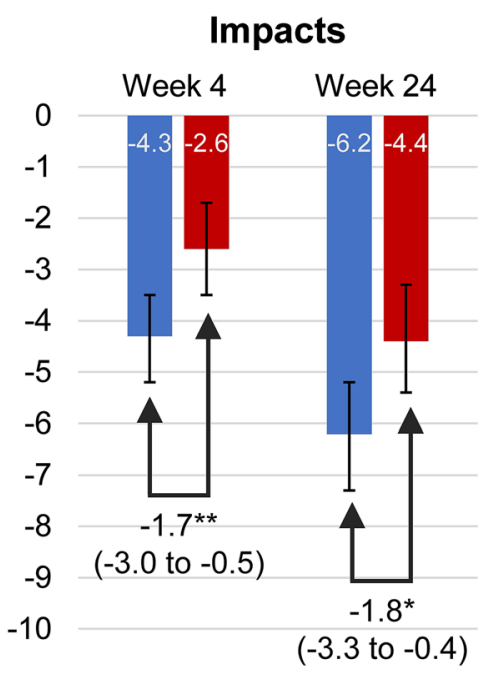

FF/UMEC/VI

BUD/FOR

$U M E C / V I$ fluticasone furoate/umeclidinium/vilanterol, $I T T$ intent-to-treat, $L S$ least squares, SGRQ St George's Respiratory Questionnaire

better response category versus a worse category for Change in Global Activity Limitation than those treated with BUD/FOR at week 24 (ITT) (ordered OR 1.58; 95\% CI 1.33-1.89) and week 52 (EXT) (ordered OR 2.15; 95\% CI 1.46-3.16).

Responses to the daily activity question were not easily interpreted as only 5\% (approximately) of patients in each group reported an improvement in the number of days they were able to perform more activities than usual. At baseline in both the ITT and EXT populations, the majority of patients in each treatment arm (55-58\%) reported a score of 1 (no effect on activities) and approximately $40 \%$ reported a score of 0 (fewer activities than normal).

At the final study visit (week 24, ITT population), of those patients who expressed a preference, more preferred the ELLIPTA ${ }^{\circledR}$ inhaler to the Turbuhaler ${ }^{\circledR}$ (Table 5).

\section{DISCUSSION}

The planned inclusion of reliable and responsive PRO tools and the prespecified analyses of 


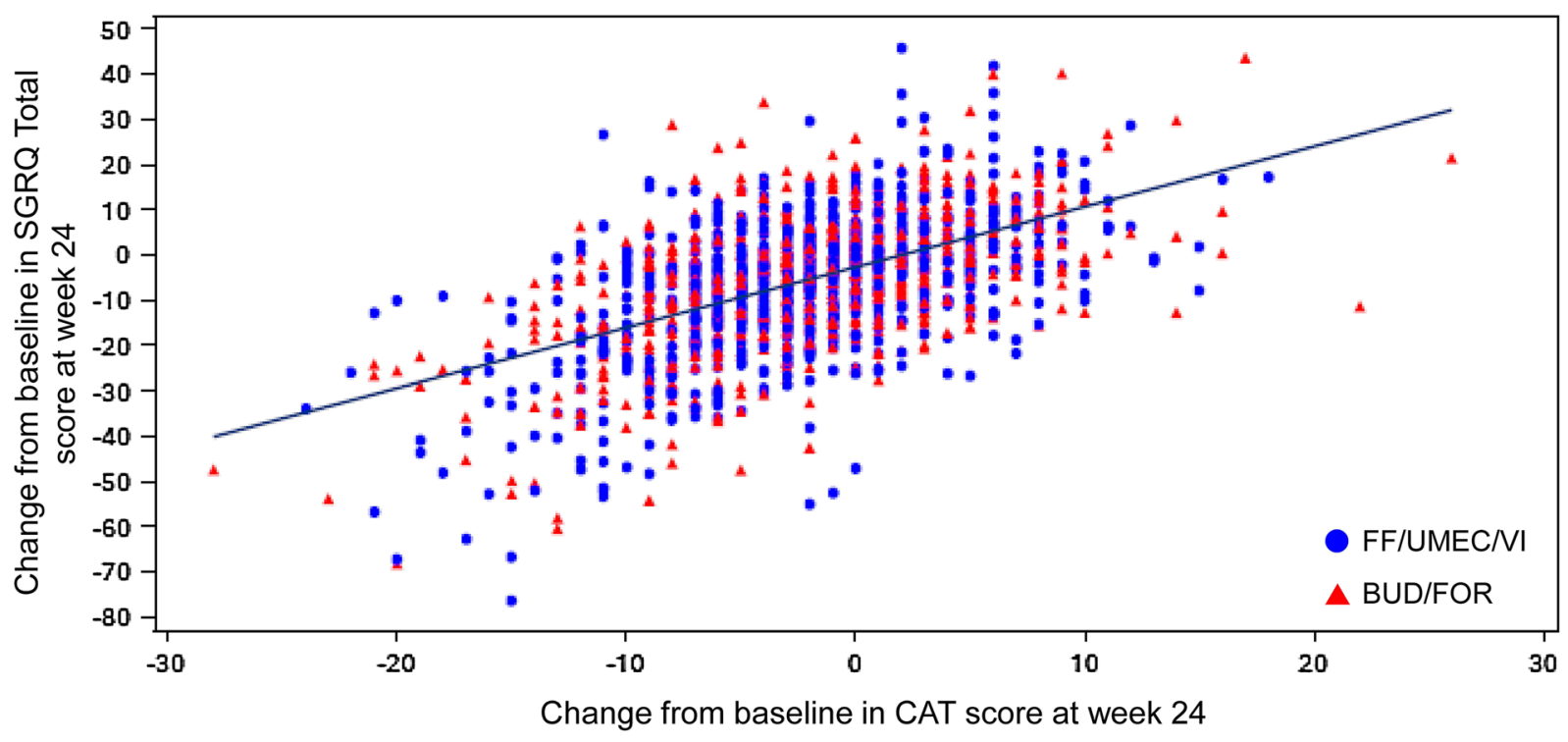

Fig. 5 Change from baseline in CAT score versus change from baseline in SGRQ total score at week 24 in the ITT population. Line represents line of best fit. Fitted regression line using the SAS procedure SGPLOT with a REG statement. $B U D / F O R$ budesonide/formoterol, $C A T$ COPD Assessment Test, FF/UMEC/VI fluticasone furoate/umeclidinium/vilanterol, ITT intent-to-treat, $S G R Q$ St George's Respiratory Questionnaire

Table 5 Inhaler preferences at week $24(n=1810$; ITT population $)$

\begin{tabular}{llllll}
\hline Factor & Completed question & Expressed a preference & \multicolumn{2}{l}{ Preference, $\boldsymbol{n}(\%)$} & \multirow{2}{*}{$\boldsymbol{P}$ value } \\
\cline { 5 - 6 } & & & ELLIPTA & Turbuhaler & \\
\hline Number of steps & 1736 & 1131 & $869(77)$ & $262(23)$ & $<0.01$ \\
Time taken & 1736 & 1114 & $853(77)$ & $261(23)$ & $<0.01$ \\
Ease of use & 1736 & 1173 & $906(77)$ & $267(23)$ & $<0.01$ \\
\hline
\end{tabular}

Percentages for ELLIPTA and Turbuhaler preferences were calculated based on the number of patients who expressed a preference

ITT intent-to-treat

these data in the FULFIL study allows the patient perception of real-life disease impact and severity to be more fully described. In the study, rapid and sustained reductions in daily symptoms assessed by the E-RS: COPD and subscales alongside improvement in HRQoL were demonstrated for both treatment groups. Although it was expected that a reduction in symptoms, particularly dyspnea, would also be reflected in improved activity levels, this was not clearly demonstrated in the daily activity question as very few patients reported the ability to perform more than usual activities. However, when responding to the Global
Rating of Change in Activity question, patients in both groups were more likely to report improved activity than reduced activity at week 24. Measurement and monitoring of activity in COPD patients is an emerging area for study; patient motivation and habit are likely to affect the magnitude of reported change [24].

In clinical studies, PRO measures provide insights into patient perception of symptom severity and changes alongside the use of physiological measures and can demonstrate the overall impact of treatment. The use of daily diary measures of symptoms such as E-RS: COPD captures time of data entry and 
minimizes patient recall issues, which can be seen with periodic assessment. It is also possible to determine the timing of symptom improvement by examining symptom patterns and stability in individual patients. Early changes to HRQoL measures (SGRQ and CAT) at week 4 are mostly driven by the reduction in symptoms, and this is reflected in the E-RS: COPD and TDI focal scores, which also show early improvement. The particular improvements in dyspnea measures for FF/UMEC/VI over BUD/FOR are expected from the addition of a second bronchodilator. The SGRQ symptoms domain and the E-RS: COPD subscales of cough and sputum and chest symptoms improve more slowly, as do the SGRQ domains of activity and impacts, which are less immediately or directly affected by bronchodilation.

In FULFIL, both treatments produced improvements in HRQoL at weeks 4 and 24, seen in improvements in both CAT scores reported here and SGRQ total scores (previously reported: FF/UMEC/VI, -4.2 and -6.6 ; BUD/ FOR, -2.5 and -4.3 , respectively) [13]. Mean changes from baseline in the FF/UMEC/VI group were statistically superior to those in the BUD/FOR group for both CAT and SGRQ total scores. However, whilst the SGRQ total score is an accepted measure of HRQoL in clinical research, the COPD-specific SGRQ is a difficult tool to use and interpret in daily clinical practice. In development, CAT demonstrated similar measurement properties to the SGRQ $[25,26]$, and in FULFIL we examined this relationship in a post hoc analysis of the ITT population. CAT is a measure that can be easily incorporated into routine clinical practice with limited additional burden on patients and healthcare professionals. This makes the results of FULFIL more immediately useful to clinicians. Furthermore, because CAT is easy to administer and interpret, it is more likely to be performed in routine care.

When comparing changes in PRO scores between treatment groups, it is important to consider whether the change from baseline within the groups is clinically meaningful, in order to provide context for the mean differences between groups. In a study comparing two active treatments, such as FULFIL, both groups in the study might be expected to improve from baseline; therefore, a responder analysis such as that reported here provides the most meaningful comparison, since achieving a between-groups difference greater than the minimal clinically important difference is not to be expected.

The prespecified analyses of PROs from FULFIL presented here build on the primary findings [13] and further demonstrate that FF/ UMEC/VI improved patient perceptions of both symptom severity and health status, compared with BUD/FOR. In addition, these results show that a larger proportion of patients preferred using the ELLIPTA ${ }^{\circledR}$ inhaler compared with the Turbuhaler $^{\circledR}$. The findings were also observed in the EXT population over 52 weeks, demonstrating that these effects were maintained over the long term.

\section{CONCLUSIONS}

These results show that therapy with once-daily triple therapy with FF/UMEC/VI improves patient symptoms and HRQoL compared with twice-daily BUD/FOR. The inclusion of patient perspectives provides the clinician with additional information to assist choice and monitoring of therapies. The findings presented here further illustrate the benefits of once-daily triple therapy in patients with symptomatic COPD who are at risk of exacerbation.

\section{ACKNOWLEDGEMENTS}

The authors thank Helen Barnacle (GSK), Rajat Mohindra (GSK), Eva Gomez (GSK, Operations Lead), Niki Day (GSK Clinical Safety Scientist), Erik Steinberg (GSK Data Quality Leader), and the FULFIL study team. We would also like to thank Veramed for support with statistical analyses.

Funding. This study was funded by GSK (ClinicalTrials.gov number NCT02345161; GSK study CTT116853). ELLIPTA $^{\circledR}$ is owned by or licensed to the GSK group of companies. Turbuhaler $^{\circledR}$ is a registered trade mark of 
AstraZeneca. GSK designed the study; collected, analysed and interpreted the data; and wrote the study report, with the involvement of external investigators. All authors were responsible for the writing of the manuscript and the decision to submit the article for publication. GSK is also funding the journal's article processing charges and Open Access fee.

Medical Writing Assistance. Medical writing support in the form of development of the draft outline and manuscript drafts in consultation with the authors, editorial suggestions to draft versions of this paper, assembling tables and figures, collating author comments, copyediting, referencing, and graphic services was provided by Alison Scott, PhD and Louise Kelly, BSc of Gardiner-Caldwell Communications, Macclesfield, UK and was funded by GSK.

Authorship. DALp and NB carried out the literature search. DALp, NL, MT, NB, and RB designed the study. DALp, NL, CQZ, MT, NB, and $\mathrm{RB}$ collected the data. DALp, NL, DALm; CQZ, NB, RB, and SP analyzed the data. All authors interpreted the data, wrote/reviewed the manuscript, and gave final approval of the manuscript. All named authors meet the International Committee of Medical Journal Editors (ICMJE) criteria for authorship for this manuscript, take responsibility for the integrity of the work as a whole, and have given final approval for the version to be published. Guarantor author: David A. Lipson.

Prior Presentations. Single inhaler triple therapy (ICS/LAMA/LABA) in patients with advanced COPD: results of the FULFIL trial. Poster presented at ERS 6 September 2016, London, UK.

FULFIL Trial: once-daily triple therapy in patients with chronic obstructive pulmonary disease, e-published 10 April 2017, Lipson DA, et al. American Journal of Respiratory and Critical Care Medicine. 2017. 10.1164/rccm. 201703-0449OC.

Single inhaler triple therapy (ICS/LAMA/LABA) in patients with advanced COPD: patient-reported symptom and inhaler preference results from the FULFIL trial. Poster presented at ATS
23 May 2017, Washington, DC, USA.

Single inhaler, once-daily, triple therapy (ICS/ LAMA/LABA) in patients with advanced COPD: health-related quality of life (HRQoL) and activity outcome results from the FULFIL trial. Oral presentation at ATS 23 May 2017, Washington, DC, USA.

Disclosures. M. Tabberer is an employee of GSK/holds shares. R. Birk is an employee of GSK/holds shares. N. Brealey is an employee of GSK/holds shares. C.-Q. Zhu is an employee of GSK/holds shares. S. Pascoe is an employee of GSK/holds shares. N. Locantore is an employee of GSK/holds shares. D. Lipson is an employee of GSK/holds shares. D. A. Lomas has received grants, honoraria, and consultancy fees from GSK and chaired the GSK Respiratory Therapy Area Board from 2012 TO 2015.

Compliance with Ethics Guidelines. The study protocol was reviewed and approved by the relevant investigational center ethics committee or institutional review board, in accordance with the International Council on Harmonisation. The study was conducted in accordance with the Declaration of Helsinki and all participants provided written informed consent.

Patient Participants. We would like to thank the patients and their families for participating in this study.

Data Availability. The datasets during and/ or analyzed during the current study are available from the corresponding author on reasonable request.

Open Access. This article is distributed under the terms of the Creative Commons Attribution-NonCommercial 4.0 International License (http://creativecommons.org/licenses/ by-nc/4.0/), which permits any noncommercial use, distribution, and reproduction in any medium, provided you give appropriate credit to the original author(s) and the source, provide a link to the Creative Commons license, and indicate if changes were made. 


\section{REFERENCES}

1. US Food and Drug Administration. Guidance for industry: chronic obstructive pulmonary disease: developing drugs for treatment. 2016. http://www. fda.gov/downloads/drugs/guidancecomplianceregulatoryinformation/guidances/ucm071575.pdf. Accessed June, 12017.

2. Perfetto EM, Burke L, Oehrlein EM, et al. Patientfocused drug development: a new direction for collaboration. Med Care. 2015;53(1):9-17.

3. Cully JA, Graham DP, Stanley MA, et al. Quality of life in patients with chronic obstructive pulmonary disease and comorbid anxiety or depression. Psychosomatics. 2006;47(4):312-9.

4. Hu J, Meek P. Health-related quality of life in individuals with chronic obstructive pulmonary disease. Heart Lung. 2005;34(6):415-22.

5. Carrasco Garrido P, Díez JdM, Gutiérrez JR, et al. Negative impact of chronic obstructive pulmonary disease on the health-related quality of life of patients. Results of the EPIDEPOC study. Health Qual Life Outcomes. 2006;4:31.

6. Balcells E, Gea J, Ferrer J, et al. Factors affecting the relationship between psychological status and quality of life in COPD patients. Health Qual Life Outcomes. 2010;8(1):108.

7. Lopez AD, Shibuya K, Rao C, et al. Chronic obstructive pulmonary disease: current burden and future projections. Eur Respir J. 2006;27(2):397-412.

8. Guarascio AJ, Ray SM, Finch CK, et al. The clinical and economic burden of chronic obstructive pulmonary disease in the USA. ClinEcon Outcomes Res. 2013;5:235-45.

9. Cazzola M, MacNee W, Martinez FJ, et al. Outcomes for COPD pharmacological trials: from lung function to biomarkers. Eur Respir J. 2008;31(2):416-69.

10. Aaron SD, Vandemheen KL, Fergusson D, et al. Tiotropium in combination with placebo, salmeterol, or fluticasone-salmeterol for treatment of chronic obstructive pulmonary disease: a randomized trial. Ann Intern Med. 2007;146(8):545-55.

11. Jung KS, Park HY, Park SY, et al. Comparison of tiotropium plus fluticasone propionate/salmeterol with tiotropium in COPD: a randomized controlled study. Respir Med. 2012;106(3):382-9.

12. Welte T, Miravitlles M, Hernandez P, et al. Efficacy and tolerability of budesonide/formoterol added to tiotropium in patients with chronic obstructive pulmonary disease. Am J Respir Crit Care Med. 2009;180(8):741-50.

13. Lipson DA, Barnacle H, Birk R, et al. FULFIL Trial: once-daily triple therapy for patients with chronic obstructive pulmonary disease. Am J Respir Crit Care Med. 2017;196(4):438-46.

14. Meguro M, Barley EA, Spencer S, et al. Development and validation of an improved, COPD-specific version of the St. George Respiratory Questionnaire. Chest. 2007;132(2):456-63.

15. Leidy NK, Murray LT, Monz BU, et al. Measuring respiratory symptoms of COPD: performance of the EXACT- Respiratory Symptoms Tool (E-RS) in three clinical trials. Respir Res. 2014;15:124.

16. Leidy NK, Sexton CC, Jones PW, et al. Measuring respiratory symptoms in clinical trials of COPD: reliability and validity of a daily diary. Thorax. 2014;69(5):443-9.

17. Mahler DA, Weinberg DH, Wells CK, et al. The measurement of dyspnea. Contents, interobserver agreement, and physiologic correlates of two new clinical indexes. Chest. 1984;85(6):751-8.

18. Witek TJ Jr, Mahler DA. Minimal important difference of the transition dyspnoea index in a multinational clinical trial. Eur Respir J. 2003;21(2):267-72.

19. Mahler DA, Ward J, Fierro-Carrion G, et al. Development of self-administered versions of modified baseline and transition dyspnea indexes in COPD. COPD. 2004;1(2):165-72.

20. Jones PW, Harding G, Berry P, et al. Development and first validation of the COPD Assessment Test. Eur Respir J. 2009;34(3):648-54.

21. Jones PW, Harding G, Wiklund I, et al. Tests of the responsiveness of the COPD assessment test following acute exacerbation and pulmonary rehabilitation. Chest. 2012;142(1):134-40.

22. GOLD. Global strategy for the diagnosis, management and prevention of COPD. 2017; http:// goldcopd.org.

23. Riley JH, Tabberer $\mathrm{M}$, Richard $\mathrm{N}$, et al. Correct usage, ease of use, and preference of two dry powder inhalers in patients with COPD: analysis of five phase III, randomized trials. Int J Chron Obstruct Pulmon Dis. 2016;11:1873-80.

24. Gimeno-Santos E, Frei A, Steurer-Stey C, et al. Determinants and outcomes of physical activity in patients with COPD: a systematic review. Thorax. 2014;69(8):731-9. 
25. Kerwin EM, Kalberg CJ, Galkin DV, et al. Umeclidinium/vilanterol as step-up therapy from tiotropium in patients with moderate COPD: a randomized, parallel-group, 12-week study. Int J Chron Obstruct Pulmon Dis. 2017;12:745-55.
26. Siler TM, Kerwin E, Singletary K, et al. Efficacy and safety of umeclidinium added to fluticasone propionate/salmeterol in patients with COPD: results of two randomized, double-blind studies. COPD. 2016;13(1):1-10. 